\title{
Mammary Gland
}

National Cancer Institute

\section{Source}

National Cancer Institute. Mammary Gland. NCI Thesaurus. Code C12367.

In humans, the glands of the breast, consisting of fibrous tissue connecting the lobes and fatty tissue in between the lobes. 